Mathematical Problems of Computer Science 54, 122--130, 2020

UDC 519.6

\title{
Automated Linescan Analysis for CMP Modeling
}

\author{
Ruben G. Ghulghazaryan ${ }^{1}$, Davit G. Piliposyan ${ }^{1}$ and Suren B. Alaverdyan ${ }^{2}$ \\ ${ }^{1}$ Mentor Graphics Development Services, 16 Halabyan, Yerevan, Armenia \\ ${ }^{2}$ Institute for Informatics and Automation Problems of NAS RA \\ e-mail: ruben_ghulghazaryan@mentor.com
}

\begin{abstract}
Many of the process steps used in semiconductor chip manufacturing require planar (smooth) surfaces on the wafer to ensure correct pattern printing and generation of multilevel interconnections in the chips during manufacturing. Chemical-mechanical polishing/planarization (CMP) is the primary process used to achieve these surface planarity requirements. Modeling of CMP processes allows users to detect and fix large surface planarity variations (hotspots) in the layout prior to manufacturing. Fixing hotspots before tape-out may significantly reduce turnaround time and the cost of manufacturing. Creating an accurate CMP model that takes into account complicated chemical and mechanical polishing mechanisms is challenging. Measured data analysis and extraction of erosion and dishing data from profile linescans from test chips are important steps in CMP model building. Measured linescans are often tilted and noisy, which makes the extraction of erosion and dishing data more difficult. The development and implementation of algorithms used to perform automated linescan analysis may significantly reduce CMP model building time and improve the accuracy of the models. In this work, an automated linescan analysis (ALSA) tool is presented that performs automated linescan delineation, test pattern separation, and automatic extraction of erosion and dishing values from linescan data.
\end{abstract}

Keywords: CMP modeling, Linescan analysis, Erosion and dishing calculation.

\section{Introduction}

Chemical-mechanical polishing/planarization (CMP) is a fundamental technique used in the manufacturing of multi-level interconnect semiconductor chips and electronic devices [1-3].

The main role of the CMP process is to achieve the smooth surface topography vital for both lithography requirements and the etch steps needed to construct multi-level interconnection wires, high-k replacement metal gate transistors, 3D stacked chips, 3D NAND memory cells, etc. CMP 
is used to improve the planarity for both front-end-of-line (FEOL) layers like shallow trench isolation (STI), and back-end-of-line (BEOL) layers like metal interconnect [2-4].

The number of components in semiconductor chips has approximately doubled every two years over the past two decades, as predicted by Moore [5]. With chip manufacturing process technology nodes scaling down, transistor sizes and spaces between them are continuously shrinking, which enables more functionality per unit area. As a consequence, the complexity of the fabrication process increases significantly, and extremely high degrees of uniformity are required for a high production yield. For example, the invention of gate-last high-K metal gate (HKMG) technology for the $45 \mathrm{~nm}$ technology node and below required the introduction of two new CMP steps into the FEOL process: poly open polishing (POP) and aluminum replacement metal gate (Al RMG) CMP [6]. Over-polishing and under-polishing of patterns, dishing of wide trenches, and erosion of oxides can affect depth of focus requirements for lithography, and create multi-layer stacking defects that lead to shorts between nearby trenches, among other issues.

Due to the complicated nature of chemical and mechanical processes that occur simultaneously during CMP, different patterns on the chip respond to polishing differently, which leads to surface profile height variations that affect the surface planarity. Using CMP models to simulate the surface profiles of production designs after CMP enables the detection of these possible CMP hotspots prior to manufacturing. During CMP modeling, the material removal rates and post-CMP surface profiles are predicted using physics-based numerical models. Detection of issues such as oxide erosion and metal lines dishing hotspots by simulation allows designers to fix them prior to manufacturing, which may significantly reduce the chip manufacturing turnaround time and cost. For this reason, CMP modeling is a crucial part of the design to manufacturing (DFM) flow at fabs.

One of the most important steps in CMP modeling is the accurate extraction of measured erosion and dishing data from surface profile linescans over a testchip. When performed manually, this step requires a significant percentage of the overall time needed to build a CMP model. Automation of both linescan analysis and the extraction of erosion and dishing values from linescans may significantly speed up the CMP model building process and improve model accuracy.

In this paper, an automated linescan analysis (ALSA) tool is presented that enables automated delineation of linescans, separation of test patterns in long linescans, and automated extraction of erosion and dishing values from linescans.

\section{CMP Modeling}

Creating an accurate CMP model that takes into account all of the complicated chemical and mechanical mechanisms is challenging, since it includes modeling of both complicated polishing processes and numerous deposition and etch processes, such as copper $(\mathrm{Cu})$ electrochemical deposition (ECD), chemical vapor deposition (CVD), high-density plasma (HDP) CVD, spin-on dielectric (SOD), etc. [2-4].

The core concept behind CMP modeling is to extract geometric characteristics from the semiconductor chip and predict post-polishing surface topography variation for each pattern dependent on its position on the chip. For that, the full chip is first divided into windows of fixed size. For each window, geometric characteristics of the pattern (like pattern density, width of polygons, space between them, etc.) are extracted and used for CMP model input (Fig. 1). 


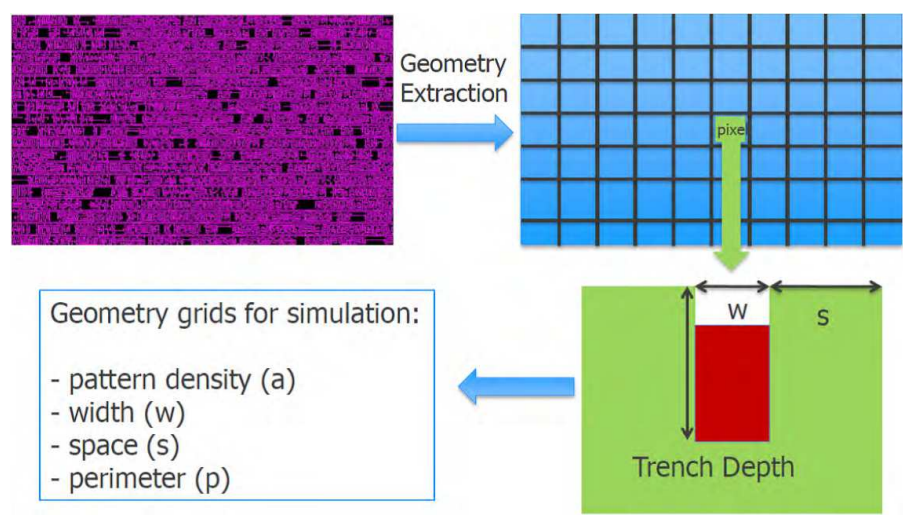

Fig 1. Geometry data extraction from a layout.

CMP modeling should not only simulate the surface profile after polishing, as determined by local geometric characteristics, but also capture CMP long-range pattern interaction effects due to pressure distribution within the die and wafer caused by pad bending and other similar effects.

\section{Measurements Required for CMP Modeling and Line Scan Data}

A key step in CMP model building is the calibration of CMP model parameters on specially designed test chips. The measurement data (erosion, dishing, and thickness) from the testchip is collected after polishing and deposition steps. An atomic force microscope (AFM) scanner or other profiler tool is often used to obtain the line scans containing erosion and dishing data of the testchip patterns (Fig. 2).

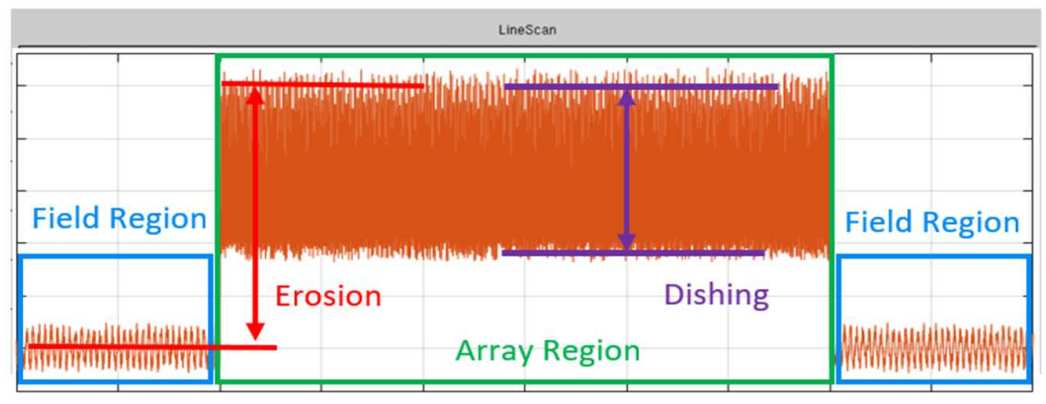

Fig. 2. Erosion and dishing data from line scans.

To obtain oxide, nitride, or metal thickness values, transmission electron microscopy (TEM) or scanning electron microscopy (SEM) cross-section images are used. The obtained measurement data is then written to measured data table (MDT) files. Next, the process recipe file containing layer stack information, deposited layers thicknesses, and CMP process conditions is created. Using the MDT and recipe file, the CMP model parameters are calibrated (Fig. 3). 


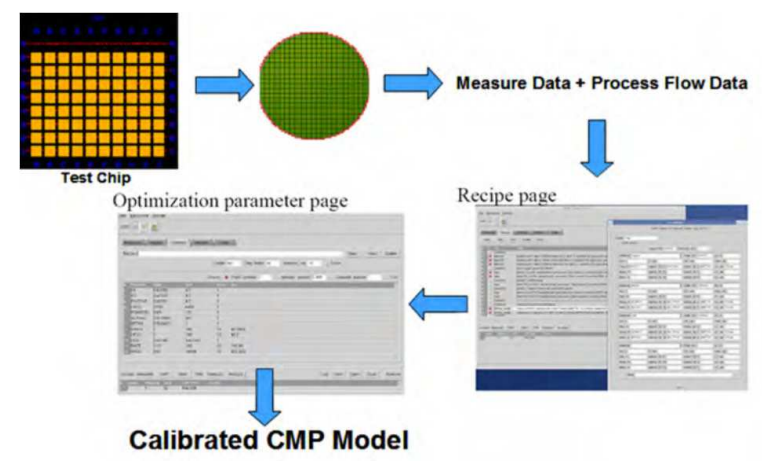

Fig. 3. CMP model building flow.

The parameter values providing the lowest root mean square error of simulated vs. measured data define the best model.

Measured erosion and dishing data are collected from specially designed test chips. The test chip size and the number of structures should provide good coverage of the width, space, perimeter, and pattern density values supported by the technology node. The CMP test chip usually consists of periodically-placed array blocks of parallel trenches with different widths and spaces between them. To get high-quality line scan data, the testchip should also contain dummy exclude areas between array blocks. The line scan over a test pattern usually has the form shown in Fig. 2. Here, a field region corresponding to either dummy fill or dummy fill exclude area is near an array region consisting of parallel trenches. The field region is used to define the reference point for erosion value detection for the array region. Meanwhile, the oscillations inside the array regions correspond to oxide-to-metal transition heights that define dishing of metal lines with respect to the neighboring oxide.

\section{Line Scans Delineation}

Extraction of measurement data from AFM or other linescans may be challenging, since the raw linescan data is usually tilted and noisy. The ALSA tool was jointly developed by IIAP and Mentor teams to accurately calculate the erosion and dishing values from linescans. In the first step, special noise reduction filters are used to reduce the noise level and remove outliers from the linescans. The tool then delineates the linescan, using specially designed algorithms based on delineation angle calculations (Fig. 4).

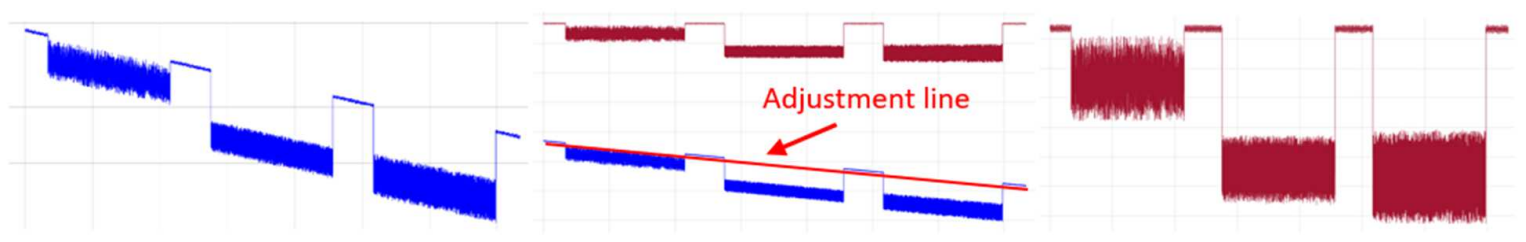

(a)

(b)

(c)

Fig. 4. Linescans (a) before and (c) after delineation. (b) Adjustment line for linescan delineation. 
When the line scan data is collected over several array regions, an automated method is required to separate field and array regions into different patterns for local erosion and dishing calculations. Using signal analysis methods, a special algorithm was developed to analyze the signal transition points of the delineated linescan and use these points to separate field and array regions. When using this algorithm, a long linescan containing multiple test patterns is divided into separate test patterns, with their array and field regions based on the transition points. For each test pattern, the array and field regions are detected and separated for erosion and dishing calculations (Fig. 5).

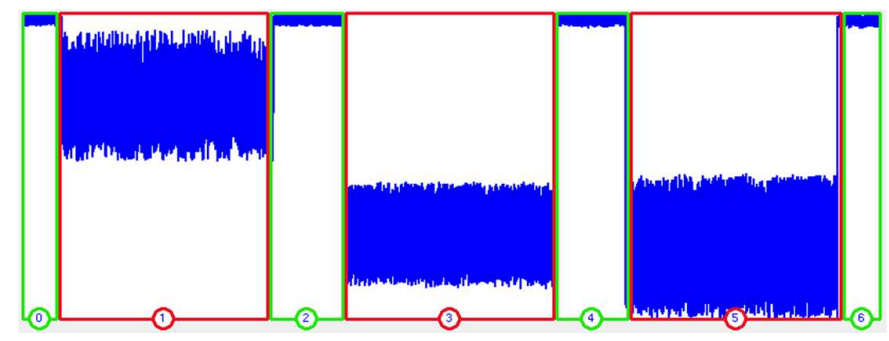

Fig. 5. Linescan with separated array blocks.

After the field and array regions of a test pattern are obtained, special algorithms were developed for erosion and dishing calculations. The algorithms are based on a projection histogram method that is applied to erosion and dishing data points from the delineated line scan. The distances between the projection histograms' maximums are used for erosion and dishing calculation. The distance between the first two local peaks from the top to the bottom of the array histogram is considered the dishing value. Meanwhile, the distance between the peak of the field and top peak of the array projection histograms defines the erosion value (Fig. 6).

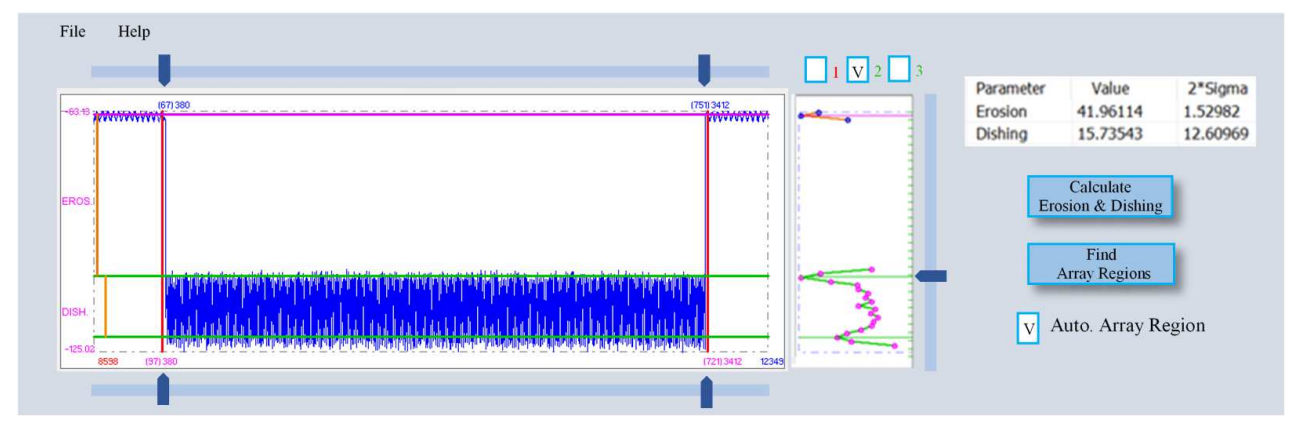

Fig. 6. Calculation of erosion and dishing values of a test pattern with field and array regions.

\section{The ALSA Tool GUI}

The ALSA tool automates all the steps mentioned in the previous paragraph. The ALSA GUI prototype, which is shown in Fig. 7, also allows modelers to perform manual corrections of delineation, erosion, and dishing values tuning, as needed. 


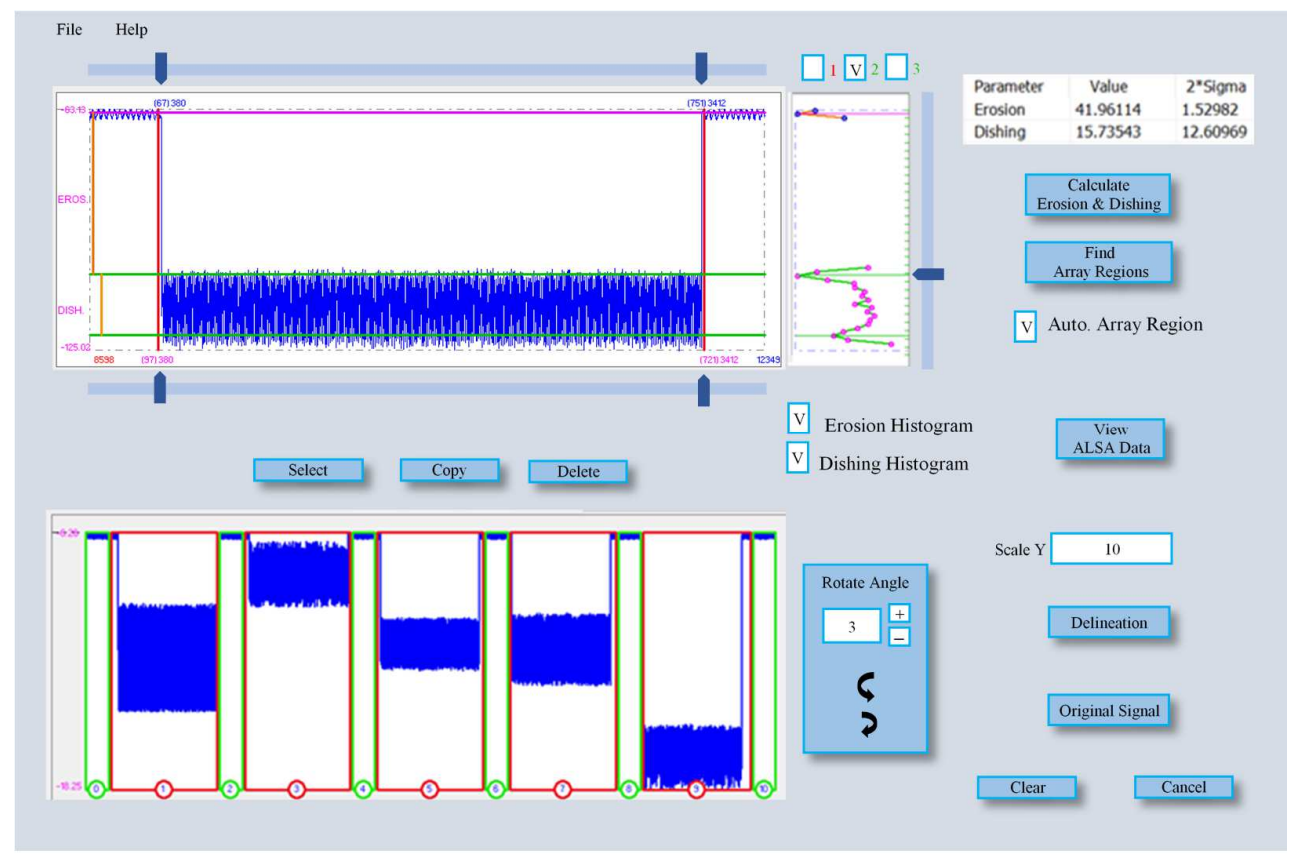

Fig. 7. ALSA tool GUI prototype.

The delineation angle and other settings used for erosion and dishing calculations can be exported into a configuration file with the ".alsa" extension. The saved configuration can then be retrieved from the file and displayed in the ALSA GUI. Fig. 8 shows examples of erosion and dishing calculations for different line scans using the ALSA tool.
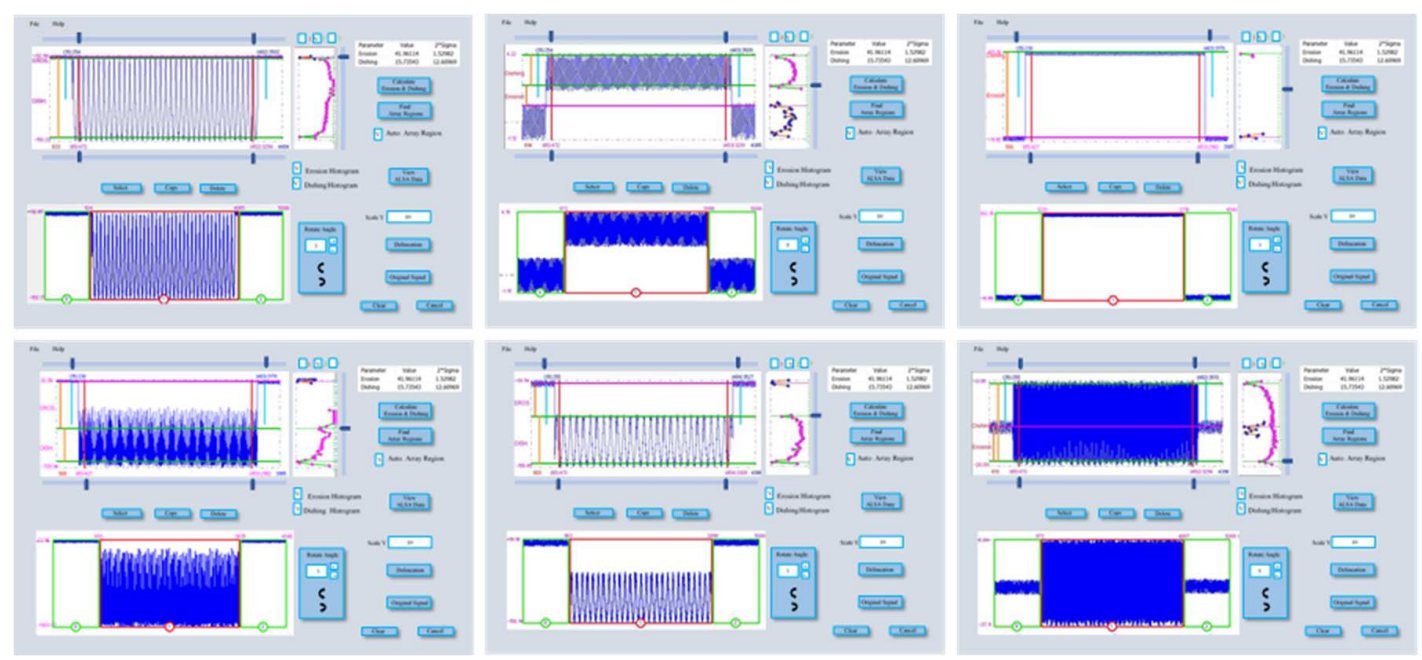

Fig. 8. Examples of ALSA tool applications to different line scans.

\section{Conclusion}

Manual extraction of the measured erosion and dishing data from surface profile linescans for CMP model building is a complicated and time-consuming process. Due to the tilt of linescans, 
and the noise in linescans, manual extraction of erosion and dishing values may lead to data errors. In this paper, we presented a new ASLA tool for automated delineation, noise reduction, test pattern separation, and extraction of erosion and dishing data for test patterns. The ASLA tool automates the extraction of test chip data to both simplify the process and improve the quality of the measurements that are critical in building high quality CMP models.

\section{Acknowledgements}

This work is done under the support of a joint collaboration project between Mentor Graphics Development Services and The Institute for Informatics and Automation Problems of the National Academy of Sciences of the Republic of Armenia. The authors would like to express their appreciations to Jeff Wilson and Simon Favre for their encouragement and support during paper preparation, and to Shelly Stalnaker for her editorial assistance in the preparation of this paper.

\section{References}

[1] M. Oliver, "Chemical-mechanical planarization of semiconductor materials", Springer Science \& Business Media, vol. 69, pp. 1-428, 2004.

[2] R. Ghulghazaryan, J. Wilson and N. Takeshita, "CMP Model building and hotspot detection by simulation", Proceedings of 158th Meeting of Planarization CMP Committee, Nagoya, Japan, vol. 55, pp. 55-59, 2017.

[3] R. Ghulghazaryan, J. Wilson and N. Takeshita. "Building CMP models for cmp simulation and hotspot detection", mentor.com, 2017.

[4] R. Ghulghazaryan, J. Wilson and A. Abouzeid. "FEOL CMP modeling: Progress and challenges", In 2015 ICPT, IEEE, pp. 1-4, 2015.

[5] G. Moore, "Cramming more components onto integrated circuits", Electronics, vol. 38, no 8, pp 114-117, 1965.

[6] M. Krishnan, J. Nalaskowski and L. M. Cook, "Chemical mechanical planarization: slurry chemistry, materials, and mechanisms", Chemical reviews, vol. 110, no. 1, pp. 178-204, 2010 .

Submitted 10.08.20, accepted 20.11.20. 


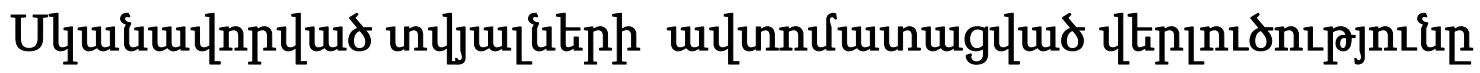

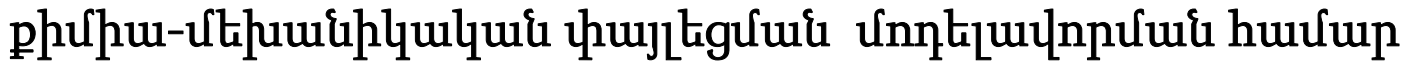

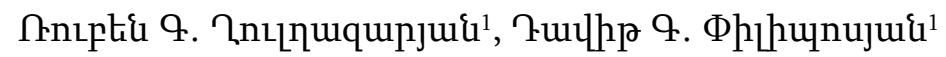

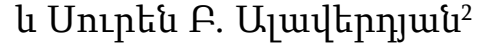 \\ ${ }^{1}$ Mentor Graphics Development Services, Ephumi, Zujuuunui

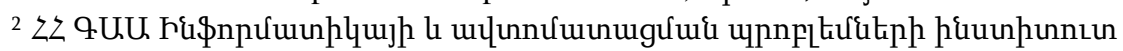 \\ e-mail: ruben_ghulghazaryan@mentor.com
}

\section{Uự̆nนhnư}

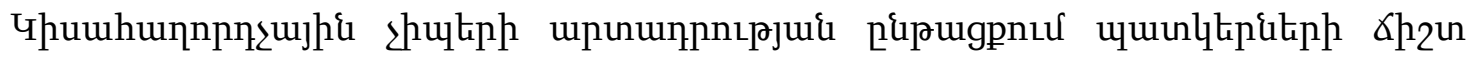

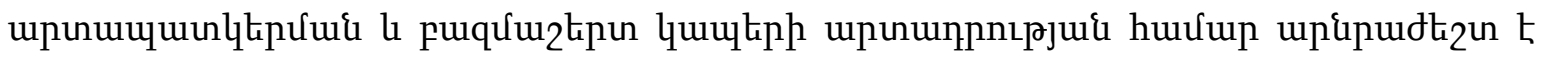

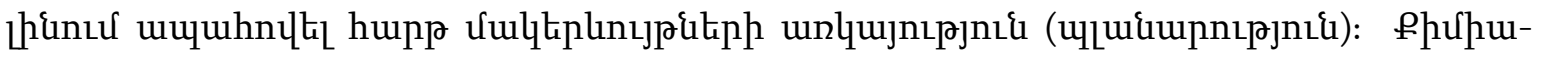

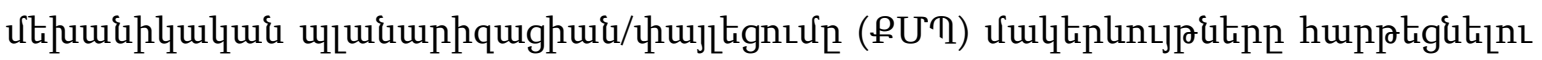

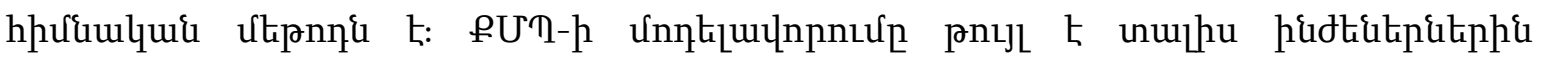

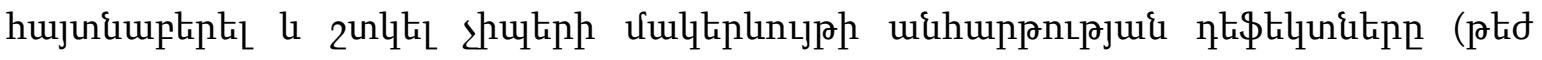

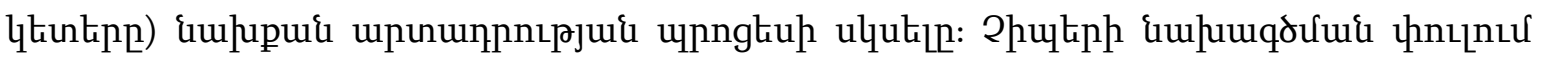

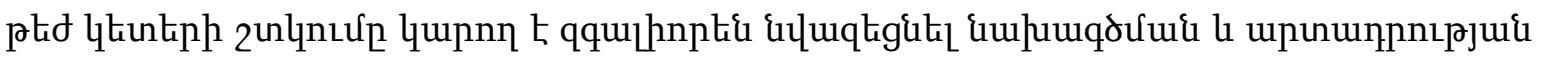

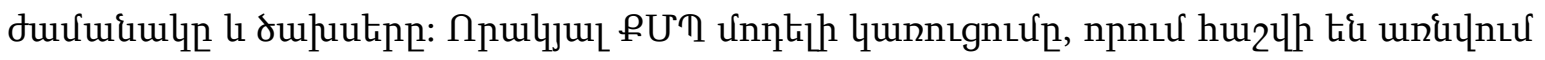

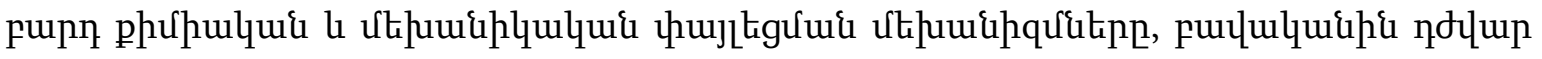

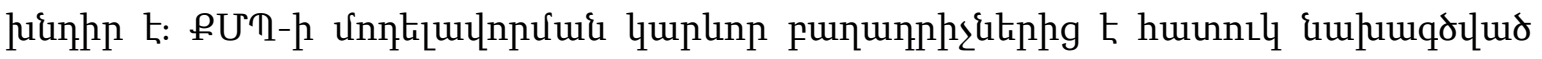

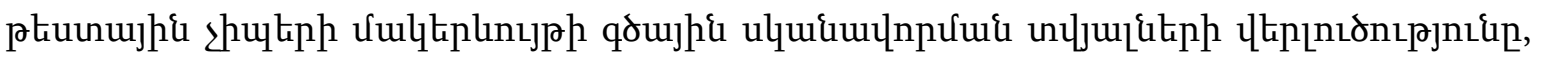

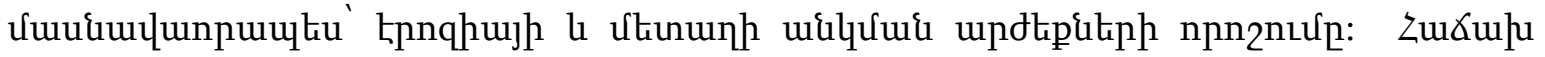

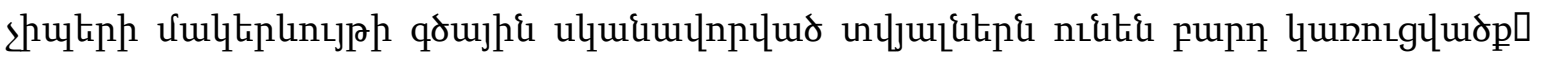

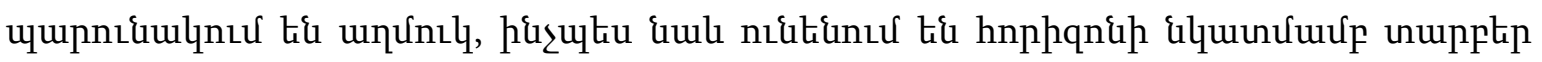

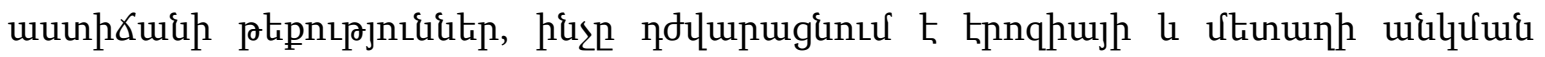

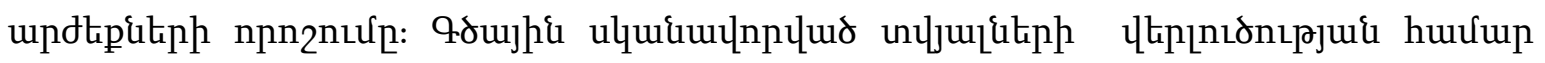

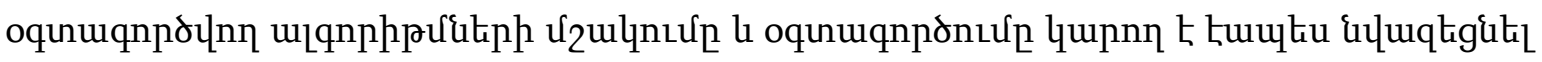

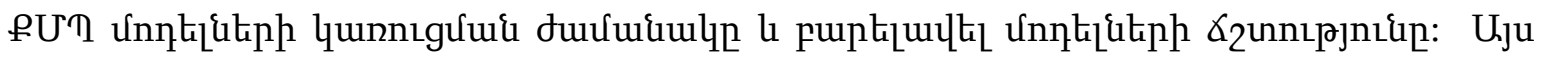

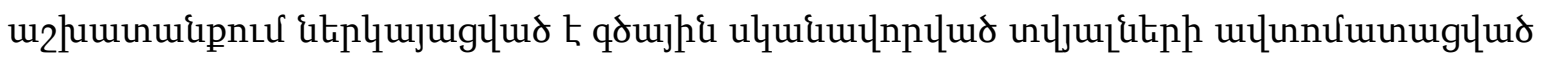

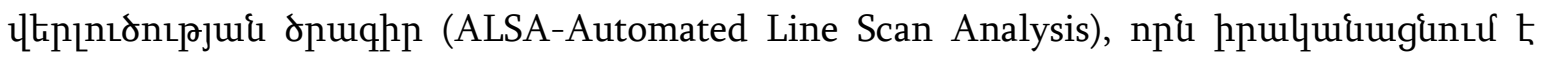

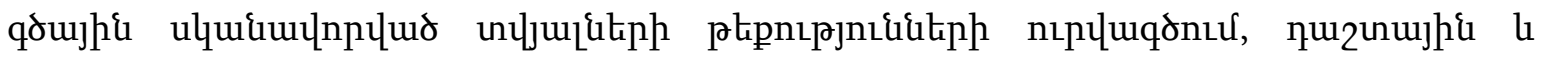

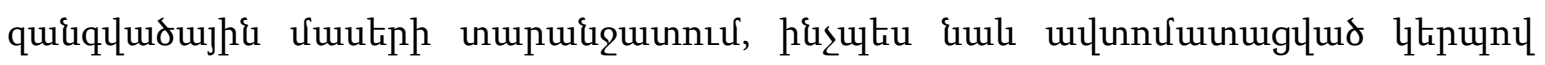

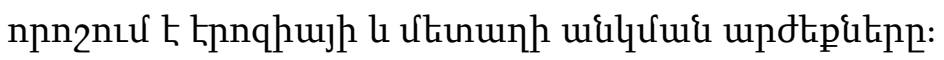

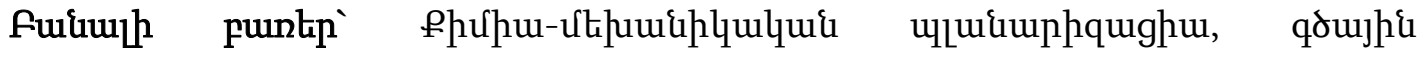

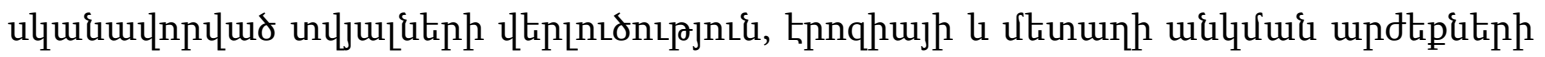
nnn2nư: 


\title{
Автоматический анализ сканированных данных для моделирования химико-механического полирования
}

\author{
Рубен Г. Гулгазарян ${ }^{1}$, Давит Г. Пилипосян ${ }^{1}$ и Сурен Б. Алавердян ${ }^{2}$ \\ ${ }^{1}$ Mentor Graphics Development Services, Ереван, Армения \\ ${ }^{2}$ Институт проблем информатики и автоматизации НАН РА \\ e-mail: ruben_ghulghazaryan@mentor.com
}

\begin{abstract}
Аннотация
Многие этапы производства полупроводниковых чипов требуют наличия плоских (гладких) поверхностей для обеспечения правильной печати дизайна и создания многоуровневых межсоединений в микросхемах. Химико-механическая полировка (ХМП) - это основной процесс, используемый в производстве для достижения требований по гладкости поверхности. Моделирование процессов ХМП позволяет пользователям находить и исправлять крупные шероховатости поверхности (горячие точки) в компоновке до производства. Устранение горячих точек до производства может значительно сократить время выполнения работ и стоимость производства. Создание качественной модели ХМП, учитывающей сложные химические и механические механизмы полировки, является сложной задачей. Анализ измеренных данных и извлечение данных об эрозии и впадин на сканированных образцах тестовых чипов являются важными этапами построения модели ХМП. Измеренные сканированные данные часто содержат шум и имеют наклон относительно горизонтали, что затрудняет извлечение данных об эрозии и впадин. Разработка и реализация алгоритмов, используемых для выполнения автоматизированного анализа сканированных данных, может значительно сократить время создания ХМП моделей и повысить их точность. В данной работе представлена программа автоматизированного анализа сканированных данных (ALSA - Automated Line Scan Analysis), которая выполняет автоматическую коррекцию наклона линейных сканированных данных, определяет границы тестовых структур, выделение полевых и матричных областей, и автоматический расчёт эрозии и впадин.
\end{abstract}

Ключевые слова: Химико-механическая полировка, анализ линейных сканированных данных, расчет эрозии и впадин. 